\title{
A publicidade contra-intuitiva: possíveis articulações e reflexos nos estigmas e estereótipos sociais
}

Francisco Leite

\section{Resumo:}

Apresenta-se neste trabalho, de forma sintética e pontual, algumas indicações sobre as noções conceituais de publicidade contra-intuitiva, os possíveis efeitos e articulação do seu discurso na reavaliação de crenças e desconstrução de estigmas e pensamentos estereotípicos sociais. Para aplicar as observações levantadas e discutir os reflexos dessa narrativa no repertório cognitivo do indivíduo e do coletivo social utiliza-se como objeto de exemplificação o composto criativo da peça publicitária impressa (revista) "Real Beleza" de Dove/Unilever para a linha Firming (2006).

\section{Palavras Chave:}

Publicidade contra-intuitiva, estigmas, estereótipos, preconceitos sociais

\begin{abstract}
:
In this article we present, in a synthetic and strict way, some indications about the conceptual notions of counterintuitive publicity, its possible effects and the articulation of its discourse in the revaluation of beliefs and deconstruction of stigma and social stereotypical thoughts. To apply the constructed observations and discuss the influence of this narrative in the individual's cognitive repertory and in the social collective, we use as a exemplification object the advertisement ad "Real beauty" from Dove/Unilever to the Firming line (2006).
\end{abstract}

\section{Keywords:}

Counterintuitive publicity, stigmas, stereotypes, social prejudice.

“A publicidade tornou-se, em nossa época, um modo dominante da comunicação e, portanto, um elemento decisivo da cultura que nos molda".

Ismar de O. Soares

Estimular o olhar social para "outros/novos" pontos de vistas é um desafio que muitas produções midiáticas estão utilizando, no contemporâneo, como estratégia para diversificar e atualizar as leituras de suas narrativas. Neste percurso pode-se perceber a força e influência desses discursos, no deslocamento e (des)contrução da percepção dos indivíduos em relação a determinados temas como estigmas, estereótipos e preconceitos sociais aplicados a específicos nichos.

As expectativas da (des)construção da percepção remetem ao atrelamento que subvertem a noção de estudos críticos contemporâneos (1). Tal termo revela-se pela articulação discursiva do atual em que realiza diferenciados olhares sobre alternativas teóricas e conceituais que implicam traços para além de pósmodernismo, pós-estruturalismo e suas adjacências. 
Em outras palavras, a utilização e a aplicação do termo destacado acima possibilita revelar através de seu sentido, novas estruturas contextuais. Já o termo deslocamento é utilizado neste trabalho como indicativo para se compreender a operação do discurso em estimular o indivíduo a interagir com seus pensamentos fixados, diante de "outras/novas" visões, abordagens. O deslocamento é ponto de partida para retirar o indivíduo de uma única visão cristalizada, o apresentando outras possibilidades, no entanto, essas novas percepções não necessariamente rompem com o pensamento inicial do indivíduo mais age como um esforço para gerar tal rompimento. Enfim, as possibilidades dessas rupturas precisam acontecer para se estabelecer diferenciadas conexões perceptivas no repertório cognitivo do indivíduo.

No desenvolvimento do ambiente midiático nacional observa-se a crescente busca de propagar, mediante esforços pontuais de comunicação, produções que abordem nas suas retóricas enunciativas a contextualização da diversidade identitária sociocultural. Tais ações são de considerável relevância, pois contribuem para os debates sobre a responsabilidade social das produções de comunicação e seus possíveis efeitos no processo de (des)construção e deslocamentos de estereótipos sociais, aos quais determinados grupos e seus integrantes estão inscritos de forma estigmatizada.

Nesta conjuntura, dentre as diversas correntes estratégicas dos meios de comunicação, a mensagem publicitária pode ser observada com destaque pela sua sintética e dinâmica forma de comunicar.

Para este trabalho a publicidade no seu viés contra-intuitivo será o foco abordado, para se desenvolver uma reflexão sobre sua possível articulação e reflexo no deslocamento e (des)construção dos estigmas e estereótipos sociais. Para se compreender os esforços da mensagem contra-intuitiva é necessário entender (ter noção) de alguns dos prováveis campos que ela atua na estrutura cognitiva do indivíduo.

\section{Estigmas, estereótipos, preconceitos, discriminação}

A proposta aqui é sugerir possíveis noções para se compreender os estigmas, os estereótipos, os preconceitos, a discriminação. Vale dizer que não é intenção deste trabalho definir uma escala de forma linear para tais fenômenos, mas sim sugerir uma possível passagem para o entendimento destes termos que muitas vezes são lidos/ vistos/entendidos como sinônimos.

O processo de aprendizado e transferência do indivíduo social depende propriamente das informações já armazenadas na sua memória (lembrar), estas que o influenciarão nas suas tomadas de decisão. Em outras palavras, as informações adquiridas anteriormente darão suporte para determinar suas escolhas de forma mais contundente. As informações codificadas durante esse processo reconstroem a memória, e não a reproduz, ou seja, as informações retidas pelo lembrar são formatadas pela reconstrução dos dados já fixados/ retidos na estrutura cognitiva do indivíduo.

É pelo processo de aprendizagem que as crenças do indivíduo são estabelecidas. Segundo Helmuth Krüger, pode-se entender por crenças "conteúdos mentais de natureza simbólica, cuja influência na cognição é manifestada na percepção e na interpretação que o percebedor faz de sua experiência social" (2004, p. 32 e 39). Ainda conforme Krüger pode-se observar as crenças por dois vieses, sendo que no primeiro elas podem ser simplesmente pessoais, quando explicitam uma avaliação ou julgamento a respeito de alguém; e no segundo quando elas também podem ser compartilhadas como no caso da opinião pública, dos estigmas e estereótipos sociais.

As crenças sempre têm sua origem nas experiências pessoais em todas as suas possibilidades (percepção, pensamento, raciocínio e imaginação). Elas se formam por associação e podem ser definidas como aquilo que 
aprendemos desde crianças e adotamos como verdade e são adquiridas nas mediações de relacionamento e aprendizagem do indivíduo: em casa com os familiares, na escola, com a mídia, em suma, no corpo social. Muitas crenças, porém são essencialistas e estão enraizadas no corpo social. Elas são exercitadas de forma explícita e muitas vezes niveladas, pelos indivíduos, via atitudes e posicionamentos em relação a determinados grupos sociais estigmatizados e considerados minoritários.

Os estigmas sociais surgem de início como prováveis elementos a serem identificados. No olhar de Goffman, os estigmas podem ser observados como "atributos profundamente depreciativos" (1978, p.13). Ou seja, os estigmas podem ser entendidos como marcas, sinais (atributos) visíveis de pertença tanto física quanto psicologicamente num indivíduo/grupo e que evidenciam as características de descrédito deste em relação a outro indivíduo/grupo.

Neste contexto, outra contribuição vem de Nobert Elias e John L. Scotson que observam efeitos dos estigmas na sociedade tendo como fator-chave o poder e seus desdobramentos inerentes, sendo "a precondição decisiva de qualquer estigmatização eficaz de um grupo outsider por um grupo estabelecido. Um grupo só pode estigmatizar outro com eficácia quando está instalado em posições de poder das quais o grupo estigmatizado é excluído" (2000, p. 23). Dessa forma é possível caracterizar os estigmas ainda segundo Goffman, como "um tipo especial de relação entre atributo e estereótipo" (1978, p.13).

Etimologicamente o termo estigma provém do latim stígma, derivado do grego stígma, que significa cicatriz, marca e o termo estereótipo é formado por duas palavras gregas, stereos, que significa rígido, e túpos, que significa traço.

Os estereótipos surgem como uma capacidade de síntese, condensação e agregação de vários elementos em uma imagem. Uma matriz que se replica. Os estereótipos podem ser definidos, segundo Krüger, "como crença coletivamente compartilhada acerca de algum atributo, característica ou traço psicológico, moral ou físico atribuído extensivamente a um agrupamento humano, formado mediante a aplicação de um ou mais critérios [...]" (2004, p. 36 e 37). Com estas definições pode-se arriscar e indicar a linha que demarca o limite entre estigma e estereótipos. Os estigmas são provavelmente os rótulos de qualificação de um indivíduo/grupo, que geralmente são depreciativos. Tais rótulos estimulam a instituição de crenças a respeito do indivíduo/grupo, sendo estas projetadas, ampliadas e compartilhadas no/pelo coletivo social mediante a formação dos estereótipos. Em outros termos, Rosana de Lima Soares, observa que em relação aos estigmas sociais "os estereótipos funcionam como reforço e manutenção de um sistema já instaurado, por meio daqueles, como diferenciador de grupos determinados" (2002).

Para o psicólogo Marcos Emanoel Pereira os estereótipos podem ser caracterizados

como artefatos humanos socialmente construídos, transmitidos de geração em geração, não apenas através de contatos diretos entre os diversos agentes sociais, mas também criados e reforçados pelos meios de comunicação, que são capazes de alterar as impressões sobre os grupos em vários sentidos (2002, p. 157).

Esta citação será o ponto cerne para o desenvolvimento das observações abordadas neste trabalho, ao focar os possíveis deslocamentos e (des)construção gerados pela recepção da narrativa publicitária contra-intuitiva.

Os estereótipos sociais são divididos em atributos positivos e negativos e sofrem também duas mobilizações: a que se dirige para o grupo ao qual o individuo pertence (auto-estereótipo); e a que indica um grupo distinto (hetero-estereótipo). Estas mobilizações, ainda, também se cruzam com os atributos positivos e negativos. A pesquisadora Patrícia Devine (1989) sugere que é a combinação de estereótipo negativo e crenças pessoais que resulta em atitudes preconceituosas. 
De acordo com Marcos Emanoel Pereira, "a noção de preconceito refere-se a uma atitude injusta e negativa em relação a um grupo ou a uma pessoa que se supõe ser membro do grupo" (2002, p. 77). A passagem entre estereótipos e preconceitos se dá segundo Krüger, "quando estiverem associados a sentimentos, os estereótipos sociais passam a constituir estruturas psicológicas de maior complexidade, caracterizadas como atitudes, preconceitos sociais" (2004, p.37). Os preconceitos sociais são atitudes e idéias rígidas com conteúdo racional e emocional negativo e injusto, que deriva dos estereótipos. Dessa forma, o preconceito pode ser entendido como uma opinião prévia, que se problematiza por um julgamento antecipado, sem base de juízos de valor, a respeito de um indivíduo/grupo de forma discriminatória.

A discriminação é o efeito imediato causado pelos preconceitos sociais é um tratamento injusto, segundo Krüger, "uma forma de relacionamento, avaliação e atendimento comparativamente desigual e desfavorável, proporcionado a uma coletividade humana ou individualmente a pessoas que a integram, precisamente porque são alvos de preconceitos sociais" (2004, p.38). A discriminação funciona como uma linha simbólica imaginária que atua de forma a separar grupos e os indivíduos que os integram em relação a outros dentro de uma matriz relacional de poder.

A partir destes fenômenos psicológicos e sociais outros podem surgir pela formação desta matriz relacional de poder, resultando, por exemplo, na exclusão social que pode ser entendida como o afastamento e privações socioculturais a determinados indivíduos/grupos, implicando a formação de grupos minoritários (minorias). Aqui este termo conceitual deve ser entendido como simbólico para representar grupos sociais que independentemente de parâmetros quantitativos, encontram-se inscritos com pouca representatividade nas esferas sociais, localizados diversas vezes à margem dos interesses da sociedade. Cabe citar como exemplo os homossexuais, os judeus, os negros e outros (HALL, 2003). Tal inscrição se estabelece via dominação de grupos hegemônicos que versam pela verticalidade ou hereditariedade atribuída pela hegemonia e subalternidade.

\section{A publicidade contra-intuitiva e suas articulações e reflexos}

A publicidade contra-intuitiva no olhar do antropólogo Peter Fry (2002, p.308), é uma tentativa deliberada de romper com os antigos estereótipos com a produção que se pode chamar de cartazes contra-intuitivos (2).Nos quais representantes de grupos minoritários têm abandonado, nos enredos publicitários, posições subalternas por outras de maior prestígio, status, sucesso.

Na perspectiva do trabalho de Peter Fry, o composto contra-intuitivo pode ser traduzido a partir do termo inglês «counter-intuitive», isto é, algo que desafia a intuição ou senso comum do indivíduo. Com a recepção/interação da mensagem publicitária contra-intuitiva pelo indivíduo tenta-se operacionalizar (deslocar) o desenvolvimento do seu pensamento, inserido no senso comum, levando-o do conhecimento superficial ao reflexivo, filosófico gerador do senso crítico. O senso comum segundo Lalande, "é o conjunto das opiniões tão geralmente admitidas, numa dada época e num dado meio, que as opiniões contrárias aparecem como aberrações individuais“ (1996, p. 998).

Buscar não desconsiderar a relevância da produção do senso comum, mas sim apresentar ao indivíduo o desafio e provocação inerente à narrativa da publicidade contra-intuitiva, que busca estimulá-lo, para que utilize ambas as formas de produção de conhecimento (senso comum e senso crítico) para (des)construir/ deslocar suas percepções e opiniões negativas sobre os indivíduos/grupos estigmatizados no ciclo social é a proposta deste trabalho.

É certo que o conhecimento do senso comum tende a ser um conhecimento mistificado e mistificador, 
mas, apesar disso e apesar de ser conservador tem uma dimensão utópica e libertadora que pode ser ampliada através do diálogo com o conhecimento científico (SOUSA SANTOS, 1988).

Esta expressão/produção publicidade contra-intuitiva é utilizada, de acordo com Peter Fry, contra o preconceito essencialista que define o papel do indivíduo na sociedade produzindo e reforçando estigmas e estereótipos, como por exemplo: o papel da mulher é ser dona de casa, submissa e atuar sempre de forma secundária nas esferas sociais; do negro é ser sempre subalterno, empregado conformado e feliz; do homossexual é ser "anormal" e com traços acentuados do sexo oposto. Esses exemplos são definidos como preconceitos (atitude de carga negativa derivada dos estereótipos). Por tanto, quanto mais essas definições forem reforçadas a esses grupos, maior é a chance de que esses enquadramentos serão sempre os primeiros pensamentos gerados ou recuperados por indivíduos que interajam com um representante desses grupos estigmatizados.

Segundo Ilana Strozenberg, "a força de atuação da propaganda pode ou reforçar preconceitos - reproduzindo estereótipos dominantes no discurso social; ou promover e fortalecer novos valores e visões de mundo abrindo espaço para outras versões da realidade" (2006).

O discurso publicitário contra-intuitivo pretende possibilitar e auxiliar na (des)construção da realidade sociocultural, ao apresentar (dar visibilidade) a "outro/ novo" ponto de vista sobre questões de preconceitos socioculturais vetorizados a determinados nichos da sociedade. A comunicação (publicidade) contra-intuitiva tem o objetivo de fomentar a revisão e a formação de pensamentos subjetivos, mediante a sua cadeia de amarrações interdiscursivas, propondo um diferenciado e atualizado olhar social/intelectual para antigas crenças e atitudes preconceituosas que estão fixadas na memória implícita e explícita dos indivíduos.

É interessante observar os prováveis efeitos que esse estilo de enredo procede no imaginário, pois o indivíduo social interage com o enunciado contra-intuitivo pelo aspecto contrário do que ele identifica nas outras publicidades, ou seja, a publicidade contra-intuitiva oferece subsídios para a produção de sentido reverso as significações que o receptor se mostra mais resistente. Pode-se dizer que com a percepção, recepção e avaliação desse discurso instaura-se uma briga entre as crenças e os valores adquiridos pelo indivíduo receptor, promovendo alterações nas suas atitudes e comportamentos.

A mensagem publicitária contra-intuitiva deve considerar como ponto conectivo para a construção ou criação de sua retórica a centralidade das crenças na ativação do estereótipo ou preconceito. Oferecendo ao indivíduo receptor desta mensagem ferramentas que justifiquem e condicione a proposta de auto-reavaliação de suas crenças para a desestabilização dos estigmas e estereótipos sociais, provocando assim "estranhamentos" dentro de um campo de oposições.

Por muito tempo a indústria cultural utilizou-se de personagens sociais hegemônicos em suas mensagens publicitárias, o que contribuiu para o enraizamento e fortalecimento social de idéias preconceituosas. Nesta conjuntura, não era reconhecida a diversidade de identidades dos grupos sociais, sendo muitos inseridos à margem desta corrente de produção mercadológica.

O objetivo da indústria cultural continua sendo pesquisar os desafios e a problemática da comunicação em prol de seu capital, porém - contudo, em suas estratégias contemporâneas é possível observar sutilmente o aumento de comunicações dirigidas a públicos diversificados. Considerando também em suas articulações representantes de grupos minoritários observados, agora, perante o mercado como relevantes consumidores.

Nesse caminho outras perspectivas também colaboram para este contexto, como a formação dos atuais profissionais de comunicação que procuram expor em suas atuais produções realidades do cotidiano das minorias socioculturais, dentro de um ambiente perceptivo diferenciado. Isto Implica a geração e estímulo de 
diversas discussões do coletivo social a respeito desta "outra/ nova" construção significativa exposta em tais discursos. Estes profissionais segundo Peter Fry são treinados nas melhores universidades onde o preconceito é discutido e condenado.

Entretanto, é bom enfatizar que o formato contra-intuitivo não se isola do objetivo principal da publicidade e propaganda que é o mercadológico. Apenas mescla-se a ele como uma "nova/outra" forma de contextualização enunciativa de temas minoritários, utilizados pelos novos e atuais profissionais de comunicação. Logo, essas produções possivelmente realizam além de sua função mercadológica, a sua contribuição social pela forma contra-intuitiva que visa estimular uma nova postura do indivíduo, diante da realidade desses nichos minoritários, contextualizada nas variadas peças comunicacionais no contemporâneo.

Por tanto, pode-se supor que além dessa nova visão dos profissionais de comunicação, mais conscientes do poder de influência que suas estratégias discursivas têm perante a opinião pública na (trans)formação e estabelecimento de parâmetros ao direcionamento social. A publicidade contra-intuitiva está se fortalecendo também pelo contínuo acompanhamento e percepção do mercado às mudanças sociais tais como: poder aquisitivo e reconhecimento do respeito devido a esses grupos minoritários pela sociedade e os danos causados pela rejeição social. Fatos impulsionados pela ativa luta organizada desses grupos para o reconhecimento e respeito de suas identidades e alteridades no meio social. Segundo o pesquisador Édison Gastaldo, "o discurso publicitário vem abandonando lógicas de persuasão racionalizantes, passando a investir na persuasão via identificação" (2004).

\section{As identidades e a publicidade contra-intuitiva}

A identidade é um tema atual e complexo muito debatido nas universidades e por cientistas sociais, que tentam estudá-la pesquisando seu desenvolvimento. Para o presente trabalho tenta-se apenas propor uma breve e geral explanação da conceituação de identidade, sem um aprofundamento, pois o que se busca neste estudo é saber como esse elemento integra e aparece numa produção publicitária contra-intuitiva.

Utiliza-se o conceito de identidade sob o olhar de Eneus Trindade, que a percebe da seguinte forma: "a identidade acontece por relações de pertencimento, que implicam o ser incluído em alguma categoria identitária. Já a relação de pertinência dá-se quando se tem o reconhecimento de algo a partir do outro, pelo outro" (2003, p. 77). Isto é, o sujeito contemporâneo só encontra a sua identidade (ele com ele) na interação com o grupo que pertence via identificação (ele com o outro).

A construção do conceito de identidade transcorre em um processo de descentramento histórico, Stuart Hall examina essa construção em três fases: do conceito ligado ao indivíduo do iluminismo, em que a identidade estabelecia-se pelo individualismo; o conceito do indivíduo sociológico que se define com a interatividade do indivíduo (eu e a sociedade); e por fim, o indivíduo pós-moderno, que não tem uma identidade fixa, e sim em constante transformação. Para o autor,

existiram cinco movimentos que determinaram essa ruptura de passagem da compreensão da subjetividade una, indivisível, para a subjetividade fragmentada, mutável e dinâmica e que repercutem no olhar epistemológico sobre as discussões da identidade do homem e do mundo contemporâneo. Esses movimentos são: a reflexão que se deu a partir do pensamento marxista; a psicanálise freudiana e sua evolução no trabalho de Jacques Lacan; a concepção de língua de Saussure; e os movimentos sociais das minorias, principalmente dos anos 60 (Hall apud TRINDADE, 2003, p. 78). 
caracteriza pela sua fragmentação e diversificação. Observar-se que o quinto movimento soma subsídios para o objetivo desta pesquisa. Os movimentos sociais de grupos minoritários (étnicos, religiosos, homossexuais, classes sociais, entre outros) refletem com precisão o conceito de identidade contemporânea, pois são grupos sociais distintos que possuem razões, ideologias e lutas específicas, e buscam o reconhecimento social, independentemente, de sua diferença e alteridade.

Ainda segundo Hall, "cada movimento apelava para a identidade de seus sustentadores. Isso constitui o nascimento histórico do que veio a ser conhecido como a política de identidade - uma identidade para cada movimento" (2003, p. 45).

A propaganda contra-intuitiva direta ou indiretamente fortalece com suas articulações, a luta pelo reconhecimento da questão do multiculturalismo, tão defendida pelos nichos estigmatizados. Em uma de suas observações a pesquisadora Kelly Prudêncio pontua que: "Nesse sentido os movimentos sociais contemporâneos não estão em busca de nenhum modelo de sociedade perfeita, mas lutam pela democratização das relações sociais" (2003, p. 96).

Em seu artigo "Estética e política: relações entre 'raça', publicidade e produção da beleza no Brasil", que integra o livro: $\mathrm{Nu} \&$ Vestido: dez antropólogos revelam a cultura do corpo carioca (2002), organizado pela antropóloga Mirian Goldenberg, Peter Fry aborda e discute a relação raça e mercado articulando todo um substrato sobre essa questão, dando enfoque ao papel do profissional de publicidade e propaganda nessa dinâmica e defendendo que "em longo prazo, a direção tomada pela publicidade será um fator poderosíssimo na definição da direção básica a ser tomada pelas relações raciais" (p. 305). Essa observação estende-se aos outros movimentos sociais que também trabalham incessantemente para alcançar os mesmos objetivos.

\section{A Real Beleza de Dove}

As mensagens publicitárias em suas diversas formas são produções que inegavelmente possuem influência na massa social. A essência da publicidade de hoje é a mesma de antigamente que apresentou, ensinou, educou e aculturou a sociedade a consumir, aceitar, conviver com novidades como: o sabonete, a pasta dentifrícia, a geladeira, microondas e outras. Os efeitos dessas mensagens implicam-se pela sua dinâmica narrativa e interdiscursiva de rápida interação e associação com a realidade percebida dos indivíduos receptores nos seus contextos sociais.

No seu viés contra-intuitivo o principal efeito social esperado pela codificação da mensagem publicitária é a quebra da associação, via reavaliação de crenças, de determinados estereótipos negativos aos quais nichos minoritários e seus membros estão inscritos na memória do receptor.

A narrativa publicitária pode ser identificada e aplicada em diversas publicidades da indústria de cosmético no Brasil. A indústria da beleza está redirecionando o desenvolvimento de suas estratégias persuasivas de comunicação para a mulher real. As fotos de mulheres quase adolescentes, de corpos e traços perfeitos, usadas nos anúncios de cosméticos já não convencem mais as consumidoras.

Longe dos estereótipos, as mulheres de verdade; bonitas, claro, mas também com rugas e outros sinais típicos da idade garantem maior credibilidade aos produtos. Foi apostando nisso, que há mais de dez anos, a Natura pioneira no uso desse posicionamento, desenvolve as campanhas publicitárias do seu creme anti-sinais Chronos (3).

De modo semelhante, em 2005, foi veiculada na mídia brasileira a campanha da Unilever que leva o tema 
"Real Beleza" para a linha de cosméticos Dove. Devido ao sucesso o tema desta campanha foi estendido a outras linhas da marca Dove e é utilizada até os dias atuais (4).

A campanha pela "real beleza" de Dove foi baseada em uma pesquisa internacional encomendada pela Unilever realizada com 3.200 mulheres de 18 a 64 anos em 10 países (5). Solicitou-se que elas descrevessem sua aparência, a maioria se julgou "média" ou "natural", com somente $2 \%$ declarando-se "bonita".

A campanha Real Beleza gera atualmente um amplo debate mundial: Será que a imagem realista da mulher vende numa sociedade obcecada pela juventude?

Conforme o jornal «The Wall Street Journal Américas», os especialistas estão divididos, porém para a maioria, as mulheres vão responder muito positivamente a marcas que utilizam estratégias que não as impõem um padrão de beleza, mas sim trabalham nos seus enunciados a beleza de uma forma diversificada e subjetiva, ressaltando as boas coisas que cada uma possui, em vez de aumentar suas inseguranças, com padrões inatingíveis.

Diante do exposto, pode-se sugerir que a real beleza vende sim, o case de Natura, por exemplo, que é sucesso há dez anos, serve como panorama mundial para se pontuar o retorno e aceitação social e mercadológica dessa estratégia ou posicionamento. A campanha de Dove vem reforçar esta tendência contemporânea, estabelecendo a posição de mulheres que querem produtos que vendam desejos e promessas, sim, porém que sejam elementos possíveis de serem atingidos e que considerem a diversidade.

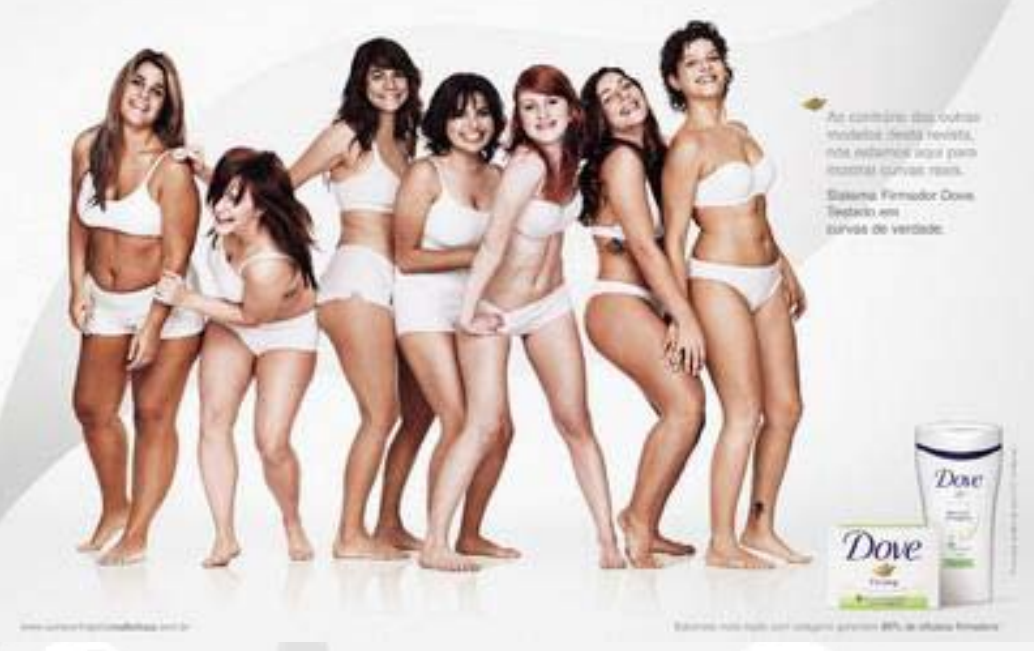

Figura 1 - Peça impressa/ Revista - Sistema Firmador Dove.

O composto criativo desta publicidade de Dove apresenta mulheres de bem com a vida e satisfeitas com sua própria beleza, expondo seus corpos e curvas de forma graciosa. A imagem por si só apresenta o conceito de diversidade. O ponto central para identificar as nuances da estratégia contra-intuitiva se dá pelas figuras das mulheres contextualizando um cartaz publicitário até então ambiente indicado/visto apenas para determinadas mulheres. O texto publicitário reforça o discurso contra-intuitivo ao instigar o receptor a refletir e questionarse sobre os atuais padrões de belezas com os dizeres:

"Ao contrário das outras modelos desta revista, nós estamos aqui para mostrar curvas reais. Sistema Firmador Dove. Testado em curvas reais." 
O filme publicitário "Real Beleza" da Unilever (2006) para a linha Dove Firming (sabonete e loção) serve de exemplo para aplicação da retórica contra-intuitiva, pois apresenta na sua narrativa indivíduos estigmatizados e estereotipados dentro de um diferenciado contexto, até então restrito apenas para integrantes de grupos hegemônicos. Seu operacional se daria pelo discurso que pretende estimular uma reflexão (deslocamento) que possibilite o processo de dissociação dos estigmas e estereótipos sociais junto ao receptor de sua mensagem. Isto mediante $\mathrm{o}$ ataque às suas crenças estereotipadas.

A publicidade contra-intuitiva aposta na diversidade identitária sociocultural para seu fortalecimento como uma estratégia mercadológica. Logo, pela força mercadológica a publicidade contra-intuitiva vai se desenvolvendo. Conforme afirma Peter Fry, "queira-se ou não o mercado é o divulgador mais eficiente de conceitos e idéias no Brasil contemporâneo" (2002, p. 305).

Enfim, apesar de não se pretender afirmar que a mensagem publicitária contra-intuitiva leve o indivíduo de forma concreta a revisão e dissociação de seus pensamentos estereotípicos (crenças) ela se torna uma ferramenta importante para a emergência de se provocar e ampliar na sociedade a formação de debates que influenciem o comportamento, opinião e o modo de perceber as realidades de grupos minoritários, construindo assim um ambiente normativo social que desencoraje e diminua o preconceito essencialista.

\section{Indicações Finais}

Em uma perspectiva genérica tentou-se apresentar neste trabalho algumas articulações e reflexos possíveis pela recepção de uma narrativa publicitária contra-intuitiva. Os reflexos cognitivos produzidos no indivíduo pela ação/exposição dos elementos que compõem a mensagem contra-intuitiva podem contribuir de forma significativa para o deslocamento (desconstrução) das crenças estereotipadas, gerando o estabelecimento de "outros/novos" sentidos. Despertando diferenciadas percepções, associações, posicionamentos e atitudes do indivíduo social. Devine propõe que o preconceito deve ser entendido como uma espécie de hábito e, como, tal, tem de ser quebrado (PEREIRA, 2004, p.84).

Diante da notória capacidade que o jogo da comunicação opera na esfera social, tanto na sua escala coletiva quanto individual/subjetiva, na (trans)formação da opinião pública, urge a necessidade de inserção de olhares críticos nas abordagens publicitárias atuais. Principalmente naquelas que não atendem aos requisitos da corrente contra-intuitiva, que é ampliar a percepção do indivíduo a respeito dos estigmas e estereótipos para além do senso comum.

Ressalta-se que uma das propostas deste trabalho foi inscrever uma leitura crítica aos atuais e futuros profissionais de comunicação, para demonstrar a relevância da sua responsabilidade social na formação (produção do saber/conhecimento), à luz da comunicação mercadológica.

Assim, a publicidade contra-intuitiva pode ser observada como uma nova ferramenta estratégica que fixa no ciclo da produção publicitária uma tendência que considera em seus enredos comerciais as diversas políticas de representação identitária, projetando um “outro/novo" sentido para a percepção dos estigmas e estereótipos negativos socioculturais. 


\section{Bibliografia:}

ELIAS, N. \& SCOTSON, J.L. Os estabelecidos e os outsiders. Rio de Janeiro: Jorge Zahar, 2000.

DEVINE, P. (1989) Stereotypes and prejudice: their automatic and controlled components. Journal of Personality and Social Psychology, 56, 5-18.

FRY, Peter. Estética e política: Relações entre "raça", publicidade e produção da beleza no Brasil. In: GOLDENBERG, Mirian. $\mathrm{Nu}$ \& Vestido: dez antropólogos revelam a cultura do corpo carioca. RJ: Record, 2002.

GASTALDO, Édison. A publicidade e movimentos sociais no Brasil: uma reflexão sobre políticas de representação. Revista de Economía Política de las Tecnologías y Comunicación. Vol.VI, n.1, Ene-Abr-2004. Site www.eptic.com.br/edison.pdf, 2004. Acessado em 29/9/2004.

GARCIA, Wilton. Cultura Midiática: Perspectivas contemporâneas. In: NOJOSA. U. e GARCIA, Wilton. Comunicação e Tecnologia. SP: Nojosas Edições, 2003.

GOFFMAN, E. Estigma. 2.ed. Rio de Janeiro: Jorge Zahar, 1978.

HALL, Stuart. A identidade cultural na pós-modernidade. Trad. Tomaz Tadeu da Silva e Guacira Lopes Louro. 7ed. RJ: DP\&A, 2003.

KRÜGER, Helmuth. Cognição, estereótipos e preconceitos sociais. In: LIMA, Marcus E. Oliveira. Estereótipos, Preconceitos e Discriminação: perspectivas teóricas e metodológicas. Salvador: EDUFBA, 2004.

LALANDE, A. Vocabulário técnico e crítico de filosofia. São Paulo: Martins Fontes, 1996.

PEREIRA, M.E. Psicologia Social dos Estereótipos. São Paulo: EPU, 2002.

PRUDÊNCIO, Kelly. Mídia e movimentos sociais contemporâneos: a luta do sujeito pela construção do significado. Revista Comunicação \& Política pela integração latino-americana. Vol. X, n. ${ }^{\circ} 3$, nova série, setembro-dezembro, 2003.

SOUSA SANTOS, Boaventura de. Um discurso sobre as Ciências.Porto - Portugal: Edições Afrontamento, 1988.

SOARES, Rosana de Lima. Estigmas da Aids: em busca da cura. Disponível em:

http://reposcom.portcom.intercom.org.br/dspace/bitstream/1904/19232/1/2002_COMUNICACOES_SOARE S.pdf - Acessado em 12/07/2007.

STROZENBERG, Ilana. Branca, preta, híbrida: qual é a cor da beleza na propaganda brasileira hoje? Revista Eletrônica de Jornalismo Científico - Dossiê Beleza - n. ${ }^{0} 78$ - 10/07/2006 (http://www.comciencia.br).

TRINDADE, Eneus. "Brasil, mostra a tua cara": a publicidade e a identidade cultural brasileira na transição secular. Tese (Doutorado em Comunicação) Universidade de São Paulo; Escola de Comunicações e Artes; SP; 2003.

\section{Notas:}

(1)É possível observar estudos contemporâneos como trabalhos desenvolvidos na área de ciências humanas, que abordam temas da atualidade sociocultural (GARCIA, 2003).

(2)Peter Fry adota esta expressão para apontar as publicidades, nas suas diversas formas, que rompem com a tradição ao expor em seus enredos representantes de grupos minoritários, principalmente, o negro, em posições de prestígio social. Ele exemplifica sua observação ao descrever alguns modelos desses cartazes produzidos na década de 1990 (FRY, 2002, p. 308 e 309).

(3)Jornal Valor Econômico, de 15/abril/ 2005, edição n. ${ }^{\circ} 1242$.

(4) Maiores informações podem ser acessadas pelo site criado pela Unilever, para as consumidoras interagirem e conhecerem mais sobre a campanha "Real beleza" - www.campanhapelarealbeleza.com.br 
(5)A referida pesquisa está disponível na íntegra no site da campanha.

\section{Mini Currículo :}

Mestrando do Programa de Pós-Graduação em Ciências da Comunicação, da Escola de Comunicações e Artes da Universidade de São Paulo (ECA/USP), na área de Interfaces Sociais da Comunicação e Bacharel em Comunicação Social - Publicidade e Propaganda, pelo Centro Universitário Salesiano de São Paulo (UNISAL). E-mail: holisticoleite@yahoo.com.br 